\title{
HERTA MÜLLER: POR UMA ETICA DA ALTERIDADE
}

\author{
Thalyta Bruna Costa do Lago ${ }^{1}$ \\ Helano Jader Cavalcante Ribeiro ${ }^{2}$
}

Resumo: $O$ presente trabalho propõe uma análise dos aspectos responsáveis por constituir uma obra autobiográfica inclinando-se, primordialmente, para o relato de si a partir do relato do outro. Para tanto, analisaremos o romance Tudo o que tenho levo comigo, de Herta Müller. Trata-se de uma obra construída através de cartas escritas por seu amigo Oscar Pastior, nas quais ele relata as experiências vividas durante o período em que foi mantido em um "gulag" - campo soviético de trabalho forçado- após o término da Segunda Guerra Mundial. Além do trauma como experiência de mudez vivida pelo jovem, a obra também se encarrega de retratar a dificuldade enfrentada por ele em retornar à família. Herta e Pastior desejavam escrever o livro juntos, no entanto, a morte de Pastior ocorrida no ano de 2006 impossibilitou que o projeto se concretizasse. Posteriormente, Herta escreveu a obra com o auxílio das cartas deixadas por ele, e é nesse ponto que devemos nos ater, pois através dele é possível começarmos a pensar sobre os jogos do discurso de si através do discurso do outro ("alteridade"), a reconstrução da memória a partir da memória do outro. A análise dos aspectos da obra se deu à luz de questões essenciais, tais como, a "ética da alteridade" de Emmanuel Lévinas, a qual nos permite compreender o processo de constituição do sujeito a partir do outro, o conceito de "trauma" de Sigmund Freud, para esclarecermos a relação existente entre o trauma e a história, o "conceito de origem" proposto por Walter Benjamin.

Palavras-chave: autobiografia, relato de si, reconstrução da memória, alteridade.

Abstract: The present work proposes an analysis of the aspects responsible for constituting an autobiographical work tending, primarily, to the self-reporting from the narrative of the other. In this way, we will

\footnotetext{
1 Graduanda em Alemão na Universidade Federal de Pelotas. thalyta.lago@hotmail.com.

${ }^{2}$ Doutor em Teoria da Literatura. Professor adjunto na Universidade Federal de Pelotas.hjcribeiro@gmail.com.
} 
analyze the novel The Hunger Angel, written by Herta Müller. The book is constituted by letters written by his friend Oscar Pastior, in which he reports the experiences lived during the period he was kept in a "gulag" the Soviet forced-labor camp - after the end of World War II. Besides the trauma as an experience of silence underwent by the young man, the work is also responsible for portraying the difficulty he faced in returning to his family. Herta and Pastior wanted to write the book together, however, the Pastior's death in 2006 made their desire impossible to materialize. Subsequently, Herta wrote the work with the help of the letters left by him, and considering this point that we must stick to, because from that we can begin to think about the speech games of self through the discourse of the other ("otherness"), the reconstruction of memory from the memory of the other. The analysis of the aspects of the work took place in the light of some essential concepts, such as Emmanuel Lévinas' "ethics of otherness", which allows us to understand the process of constitution of the subject from the other, the Sigmund Freud's concept of "trauma" to clarify the relationship between trauma and history, the "concept of origin" proposed by Walter Benjamin.

Keywords: autobiography, self-report, reconstruction of memory, otherness.

\section{Introdução}

A palavra contato, originada do latim CONTACTUS, é utilizada para designar uma situação em que dois ou mais seres ou corpos se tocam. Para, além disso, tal substantivo reflete também necessidades vitais ao ser humano: o contato com o mundo no qual se está inserido e com as coisas que a ele pertencem e, primordialmente, a contiguidade com o outro. Nós, enquanto seres plenamente sociais, construímos nosso conhecimento de mundo através das nossas relações interpessoais, partimos da pluralidade para que então possamos nos constituir enquanto indivíduos singulares, ou seja, a relação de contato com o "Outro" é o que permite que eu seja um "Eu".

Dado o grau de relevância exercido pelo contato com o "Outro" dentro do processo de constituição da individualidade, torna-se substancial compreendermos a forma com a qual essa relação ("EuOutro") se configura e, nesta lógica, nos valeremos da "Ética da alteridade" a qual nos é apresentada pelo filósofo lituano, Emmanuel Levinas. A "Ética da alteridade" decorre de um questionamento 
cometido por Levinas a respeito do pensamento filosófico do Ocidente cuja principal crítica é direcionada ao discurso antológico enquanto único pensamento predominante dentro da história ocidental. A preponderância de tal pensamento tornar-se problemática por esse desprezar integralmente a presença do "Outro" e designar todo mérito ao "Eu-mesmo", ou seja, o "Eu-mesmo" se prevalece em detrimento do "Outro". Segundo Bosco Batista em seu trabalho intitulado Esquecimento do "Outro" na história do Ocidente: uma abordagem do pensamento de Levinas:

O filósofo critica o antologismo como único modo de pensar que predominou na história do Ocidente e que determinou as relações históricas entre os povos que detinham o conhecimento e o poder e os povos que simplesmente eram ignorados ou violentados em sua dignidade e individualidade (BATISTA, 2002, p. 41).

Bosco Batista afirma ainda que "o argumento do autor é o de que a antologia reduz à existência do "Mesmo" tudo que é relação, negando a irrupção do diferente, da diversidade, isto é, do "Outro" em sua radicalidade.".

Com o desígnio de conceber uma consciência ética nas relações que se estabelecem entre o "Eu-mesmo" e o "Outro", de maneira que o "Eu" assuma uma postura receptiva ao "Outro", nos é apresentada então a ética levinasiana. De acordo com Martins Ribeiro, "Levinas propugna a recuperação da relação humana através do caminho que passa pelo "Outro" e extravasa o pensamento da autonomia do sujeito" (RIBEIRO, 2015, p. 70). A "Ética da alteridade" atua, portanto, na gênese da responsabilidade social, pois nessa, de forma distinta à expressa na ontologia da totalidade, o "Outro" recebe visibilidade e passa a ser reconhecido como aquele cuja presença muitas contribuições fornece para o meu processo de constituição enquanto indivíduo impar.

A base de tal modelo ético é constituída pela noção de "infinito", que é responsável por englobar tudo àquilo que excede a totalidade do "ser" em sua finitude, pela "transcendência", não encarada pelo viés religioso e sim somada à noção de infinito para designar a exterioridade do "Outro", e pela "exterioridade".

À luz desse modelo ético e a fim de compreendermos o processo de constituição de "si-mesmo", mais especificamente, a partir do relato do "Outro", trabalharemos com o romance Tudo o que tenho levo comigo, de Herta Müller. Trata-se de uma obra constituída através de cartas escritas 
pelo amigo de Herta, Oscar Pastior (que é tratado como Leo Auberg dentro da obra), nas quais ele relata suas experiências durante o hiato de cinco anos em que foi mantido em um "gulag" (antigo campo soviético de trabalho forçado).

Nosso objeto de análise conta com quarenta e quatro capítulos nos quais o jovem Leo nos apresenta as inúmeras dificuldades que the acompanharam desde o dia em que foi retirado do seio de sua família, no auge de seus 17 anos, e deportado para o campo de trabalho. Dentre os aspectos marcantes dos quais a obra dispõe, encontram-se a presença do narrador de primeira pessoa com fortes marcas autobiográficas, embora seja uma obra biográfica, a manifestação da alteridade em diversos momentos que vão para além do processo no qual ela foi constituída, e a predominância de uma linguagem poética que cumpre com excelência o dever de constituir imagens dialéticas capazes de instigar nosso senso crítico.

Similarmente, é valoroso compreendermos que ao tomar pra si o desafio de reconstruir a memória a partir da memória do "Outro", Müller não somente mantém as experiências de Pastior vivas, mas também passa a ter ciência das feridas que marcam sua própria existência, haja vista o fato de sua mãe, assim como seu amigo, ter sido mantida em um campo de trabalho soviético. Porém após a libertação, ela tomou pra si o silêncio absoluto e optou por nunca dizer uma palavra sequer sobre o assunto.

Para nos debruçarmos diante das produções literárias de Herta Müller é essencial que tenhamos não somente muita sensibilidade e um olhar crítico a respeito, mas também conhecimento sobre as vivências pessoais da autora. Vivencias essas que muitas contribuições fornecem à sua escrita.

\subsection{Herta Müller}

A poeta, ensaísta e escritora Herta Müller nasceu em 17 de agosto de 1953 em uma pequena comunidade de descendentes de alemão na Romênia. Suas obras carregam uma denúncia sobre as condições de vida impostas na Romênia durante a ditadura comunista de Nicolae Ceausescu. Durante esse regime a autora sofreu perseguição por parte do governo após se negar a trabalhar como informante e, consequentemente, teve suas obras censuradas.

O uso da linguagem poética é uma marca registrada nas produções realizadas pela autora e podemos pensar que tal linguagem exerce a função de coeficiente no sentido da responsabilidade ética. Friesen Blume 
(2013) salienta que "poucos autores são dotados da capacidade de empregar o autobiografismo de forma poética em seus ensaios com a intensidade que Herta o faz". E admite ainda que através de seus ensaios, Müller expõe fatos importantes de sua vida, tais como o de que "seu pai era soldado nazista ou que ainda viveu 20 anos após o fim da guerra como alcoólatra; [...] e que ela mesma foi ameaçada de tortura e morte em muitos dos interrogatórios da polícia secreta romena" (BLUME, 2013, p. 56). Certamente essas vivências impactaram não somente as obras concebidas pela autora, mas também os artifícios dos quais ela se vale para produzi-las, a linguagem que ela adota dentro desse processo e, principalmente, o resultado dessa junção. E tendo ciência do papel social exercido por essas produções, torna-se pertinente entendermos a forma como a crítica se configura.

\subsection{Por que as imagens se posicionam?}

Neste ponto nos colocamos diante da forma de atuação das imagens dentro obra a fim de compreendermos o grau de importância exercido por elas e, principalmente, o cuidado por parte da autora com a forma com que elas se instituem. $O$ que nos permite pensar que as imagens se posicionam?

À luz de Walter Benjamin torna-se possível deslindarmos tal questionamento. Neste sentido, lançaremos mão de dois questionamentos benjaminianos cruciais, são eles o "conceito de origem" e a "imagem dialética".

Usualmente o termo "origem" é utilizado para referenciar a gênese de um processo contínuo. Não obstante, ao nos apresentar o "conceito de origem", Benjamin acaba por atribuir um novo sentido ao termo, sentido esse que nenhuma relação possui com o nascimento das coisas. Em conformidade com Didi-Huberman, a "origem", para Benjamin, não é nem ideia e nem "fonte", ou seja, não se trata de uma ideia da razão abstrata bem como "não diz respeito a uma "fonte" de razão arquetipal". Seria então essa diretamente ligada àquilo que está em vias de transformar-se, prestes a "vir a ser". "(...) é um turbilhão no rio do devir, e ela arrasta em seu ritmo a matéria do que está em via de aparecer" (DIDIHUBERMAN, 2002 p. 170), admite Benjamin. Didi-Huberman afirma ainda, em torno de Benjamin, que:

[...] A origem surge até nós como um sintoma. Ou seja, uma espécie de formação crítica que, por um lado, perturba o 
curso normal do rio (eis aí seu aspecto de catástrofe, no sentido morfológico do termo) e, por outro lado, faz ressurgir corpos esquecidos pelo rio ou pela geleira mais acima, corpos que ela "restitui", faz aparecer, torna visiveis de repente, mas momentaneamente: eis aí seu aspecto de choque e de formação, seu poder de morfogênese e de "novidade" sempre inacabada, sempre aberta, como diz tão bem Walter Benjamin (DIDI-HUBERMAN, 2002 p. 171).

Do mesmo modo, Cavalcante Ribeiro (2013) reitera que:

Essa origem é, portanto, dinâmica, móvel, não se deixa fechar por nenhuma tentativa de totalidade.

É processo intermitente que impede qualquer modelo de fechamento, é um projeto que, quando ameaça findar, aponta para outra direção (RIBEIRO, 2015 p. 4).

É passível de compreensão, em vista disso, que ao ocupar-se daquilo que se encontra em vias de transformação, a "origem" contribui diretamente com o advento da formação crítica, isso porque a crítica nos possibilita romper com o "curso normal do rio" ao passo que traz à tona "os corpos esquecidos". Trata-se de um movimento contínuo, inacabado, no qual, a todo o momento, somos instigados a lançar um novo olhar sobre esse "curso normal" e assim, realizar contribuições que tornam evidentes os "corpos esquecidos", e mantém intacto esse "turbilhão". E é nas imagens que se originam a partir dessa movimentação que a dialética encontra espaço para se efetivar.

Ao nos colocarmos diante de alguns fragmentos do romance de Müller notaremos que a autora soube manejar com sensatez e delicadeza esse elemento crítico dentro da obra. E o termo "delicadeza" aqui não faz jus a algo meramente frágil e sim faz menção à linguagem utilizada, a qual embora seja poética, executa com maestria o propósito de nos causar incômodo diante dos relatos do jovem Leo, ou seja, nos instiga a colocar um posicionamento crítico sobre elas, ainda que esse posicionamento ocorra de forma involuntária.

O primeiro fragmento a receber atenção foi retirado do capítulo intitulado Sobre o Anjo da Fome. O "Anjo da Fome", assim como o jovem Leo, dispõe de alto grau de relevância dentro da narrativa. Trata-se de alguém cuja companhia, embora indesejada, fez-se presente durante todo 
o período de estadia no campo de trabalho. A imagem desse anjo nos é apresentada com o uso do nome próprio demarcado pela primeira letra em maiúscula ("Anjo da Fome") e a partir das menções que lhe cabem torna-se evidente seu poder de exigência para com os internos. Assim como os soldados são responsáveis por garantir o perfeito funcionamento do campo de trabalho, o "Anjo da Fome" se responsabiliza por determinar o que deve ou não ser feito para que mais um dia de sobrevivência seja alcançado. Ele nos aparece personificado e por isso se vale do direito de aconselhar, de exigir e até mesmo de advogar. É ele quem desperta e controla a maioria dos anseios e vontades naqueles que ocupam a posição de servir.

A fome está sempre ali.

Como está ali, ela vem quando e como quer.

O princípio de causalidade é o trabalho ignóbil do Anjo da Fome.

Quando ele chega, chega com força.

É claríssimo:

1 movimento completo com a pá $=1$ grama de pão.

Eu não precisaria da pá de coração. Entretanto, minha fome depende dela. Eu gostaria que a pá de coração fosse a minha ferramenta. Mas ela é o meu senhor. A ferramenta sou eu (MÜLLER, 2011, p. 88).

O segundo fragmento foi retirado do capítulo intitulado Do próprio pão ao pão da face. Nele podemos inferir aspectos que salientam a ideia proposta no fragmento anterior, a severidade do "Anjo da Fome" constitui um fator determinante quanto às ações dos que estão submetidos a ele.

Todos caem na armadilha do pão.

$\mathrm{Na}$ armadilha de manter-se firme durante o café da manhã, na armadilha da troca de pães durante o jantar, na armadilha da noite com o pão economizado debaixo do travesseiro. A pior armadilha do Anjo da Fome é a da firmeza: Ter fome e ter pão, porém não comê-lo. Ser mais duro consigo mesmo do que a terra congelada. Todas as manhãs o Anjo da Fome nos fala: Pense na noite (MÜLLER, 2011, p. 122). 
Em vista dos fragmentos apresentados, é possível começarmos a relacionar as imagens constituídas por Mülller com a força das "imagens dialéticas” propostas por Benjamin. De acordo com Didi-Huberman (2002):

(...) E por que, neste sentido, uma imagem autêntica deveria se apresentar como imagem crítica: uma imagem em crise, uma imagem que crítica a imagem - capaz, portanto, de um efeito, de uma eficácia teóricos -, e por isso uma imagem que critica nossas maneiras de vê-la, na medida em que, ao nos olhar, ela nos obriga a olhá-la verdadeiramente. E nos obriga a escrever esse olhar, não para "transcrevê-lo" (DIDI-HUBERMANN, 2002, p. 171-172).

A "imagem dialética" carrega em seu âmago a tríade constituída por tese, antítese e síntese a qual assegura sua autenticidade, ela é, no entanto, contra a linearidade da Aufhebung. Por ser dialética, desconhece a neutralidade e nos incita a estabelecer diálogo de maneira que sejamos retirados de nossas zonas de conforto. Incomodam-nos a ponto de tomarmos um posicionamento crítico diante delas, ainda que isso ocorra de forma involuntária.

\subsection{Freud entre o "trauma" e a história}

Cientes de que o surgimento do nosso objeto de análise decorre de um conjunto de inúmeras experiências marcantes vividas pela personagem principal e a fim de percebermos o impacto gerado por tais vivências, lançaremos mão da "teoria do trauma" proposta por Fred, a qual posteriormente originou o que hoje conhecemos por "teoria da psicanálise" e se relaciona de forma direta com o conceito de "memória", igualmente apresentado por ele.

A princípio, a "teoria do trauma" se ocupou de abordar as histerias afetadas por recordações do passado mantidas na memória, muitas vezes relacionadas às experiências de abuso sexual, o que denota seu caráter patogênico. Seguidamente, após a ampliação do campo de trabalho, os olhares se voltaram para a averiguação da realidade psíquica e então, a busca por cenas de abuso sexuais infantis que possam ter sido responsáveis por causar o trauma é abandonada e abre caminhos para o conceito de transferência, no qual a recordação se manifesta através do ato de repetir a ação com o desígnio de trazer à consciência as ações 
recalcadas. $\mathrm{O}$ conceito de transferência, então, pouco a pouco, passou a permear as relações terapêuticas.

Uma mudança especifica na teoria do tratamento analítico, tida como "contratransferência", estabelece uma distanciação para com o passado e uma aproximação do momento do "agora”. E embora as recordações individuais relacionadas às histórias de vida tenham sido desprivilegiadas no âmbito da terapia central, essas ainda se mantiveram como algo que necessitava ser abordado na esfera de traumatização de pessoas. Werner Bohleber (2007) admite que "Freud voltou a se ocupar do tema do trauma muitas vezes, sendo levado a isso principalmente pela catástrofe da Primeira Guerra Mundial e pela barbárie do nacionalsocialismo que se anunciava, porém, nunca sistematizou uma teoria do trauma”. Os inúmeros acontecimentos desastrosos que marcaram o século $\mathrm{XX}$, tais como a Guerra e o Holocausto, causaram sérios danos psíquicos e fez-se necessário, então, que um novo olhar fosse lançado para essas traumatizações a fim de compreendê-las de uma forma mais concreta.

A concepção que nos proporciona contribuições diz respeito ao "modelo de trauma da teoria de relações objetais". Nesse modelo, os "objetos" dizem respeito a tudo aquilo que foi vivido, tudo o que foi visto e ouvido, ou seja, todas as experiências que nós, indivíduos, introjetamos e estabelecemos relação de objeto. Esses "objetos" podem ser bons ou ruins e nós incorporamos ambos os aspectos no nosso psiquismo. As relações que estabelecemos com bons objetos resultam de experiências agradáveis que tivemos. Ao passo que as nossas relações com os objetos ruins resultam de experiências "traumáticas" às quais fomos submetidos. O “trauma” está na origem, permanece ali recalcado e retorna.

O nível de gravidade ocasionado pela situação "traumática” é proporcional aos danos que ele é capaz de causar tanto internamente quanto em aspecto interpessoal, conforme Werner (2007):

A díade comunicativa entre o self e seus objetos internos bons se rompe, levando a um estado de absoluta solidão interna que traz consigo um estado de desconsolo externo. O objeto interno bom, mediador empático entre o self e o meio ambiente, emudece, e a confiança na presença permanente de bons objetos, que cria a expectativa de empatia com o semelhante, é destruída [...] (WERNER, 2007, p. 154-155). 
Dentro da narrativa, essa categoria traumática se torna evidente no momento em que Leo, após muitos anos sem nenhum contato com a família, retorna ao lar e se choca com uma realidade completamente desconforme a que ele havia deixado. Sua família já não tinha esperanças de um dia reencontrá-lo, pois a falta de notícias os fez abraçar a certeza de que esse havia morrido. O jovem passa, então, a ter dificuldades de se incluir novamente naquele contexto, o que podemos evidenciar na seguinte citação: "Nada me interessava. Eu estava trancado em mim mesmo excluído de mim mesmo, eu não pertencia a eles, e sentia minha própria falta” (MÜLLER, 2011, p. 272).

Durante a estadia no campo de trabalho, não houve um dia sequer em que as lembranças da família e a saudade de casa não o acompanhassem e a frase de despedida proferida por sua avó ("eu sei que você vai voltar"), no dia em que foi deportado, o motivou a lutar contra a morte e resistir em meio a condições insalubres e desumanas. Ao regressar, porém, a personagem vive a frustração diante da falta de afeto dos familiares para com ele. Sente-se substituído desde o processo de tomada de consciência da existência de seu irmão, tido como o "irmão substituto", se queixa que há meses não recebe nenhuma demonstração de afeto e em um dado momento até ousa comparar-se como um dos móveis da casa em vista disso.

Além do intenso processo de cobranças internas geradas a partir disso, toda essa solidão desencadeia também o retorno do "trauma", no sentido de mesmo após a libertação, o jovem memorar com regularidade aspectos referentes ao campo de trabalho. Por exemplo, no momento em que Léo começa a trabalhar em uma fábrica de caixas, emprego que lhe foi conseguido por um tio, e necessita fazer o serviço de forma ágil, vem à tona uma série de lembranças das exigências impostas pelos soldados e ele passa a comparar a agilidade em montar as caixas com "1 movimento completo com a pá = 1 grama de pão” (MÜLLER, 2011 pág. 88). Essa é, de certa forma, a tarefa dessas imagens dialéticas. Para que possamos imaginar o inimaginável é preciso fazê-lo através de imagens potentes. E se o real lacaniano é o absurdo, o trauma, e sua representação é uma tarefa já fadada ao fracasso, é possível que tenhamos apenas um indício, uma indicação da barbárie através dessas mesmas imagens, que, apesar de tudo, são imagens, apenas imagens. 


\section{REFERÊNCIAS BIBLIOGRÁFICAS}

BATISTA, J.B. O esquecimento do "outro" na história do Ocidente: uma abordagem do pensamento de Levinas. In: X Encontro Nacional de Filosofia da ANOF, São Paulo, 2002. Resumo expandido. Perspectiva filosófica, Vol. IX - n¹8 39 - 51 Julho- Dezembro 2002.

BLUME, R.F. Herta Müller e o ensaísmo autobiográfico. Pandaemonium, São Paulo, v. 16, n. 21, Jun/2013, p. 48-78.

BOHLEBER, W. Recordação, trauma e memória coletiva: a luta pela recordação em psicanálise. Revista Brasileira de Psicanálise, São Paulo, V.41 Págs. 154-175 Mar.2007 < http://rbp.org.br/> acessado em 05/05/2017.

COSTA, J.X.S.; CAETANO, R.F. A concepção de alteridade em Levinas: caminhos para uma formação mais humana no Mundo Contemporâneo. Revista Iguarapé, Rondônia. No03, Maio de 2014 . ISSN 2238-7587 <http://www.periodicos.unir.br/index.php/igarape> acessado em 05/ 04/2017

DIDI-HUBERMAN, G. O que vemos o que nos olha. São Paulo: Editora 34, 1998.

GOMES, C. S. C. L. B. Lévinas e o outro: a ética da alteridade como fundamento de justiça. Dissertação - Pontifícia Universidade Católica do Rio de Janeiro. Rio de Janeiro, Março de 2008.

MÜLlER, H. Tudo o que tenho levo comigo. Companhia das Letras, 2011. 298 páginas.

RIBEIRO, H.J.C. Thomas Bernhard: entre máscaras e ruínas dialéticas. Revista investigações, Pernambuco, Vol.28 n¹ 1-34 Janeiro/2015.

RIBEIRO, L.M. A subjetividade e o Outro: Ética da responsabilidade em Emmanuel Levinas. №1. Ideias e Letras, 2015150.

Origem da palavra acessado em 30 de Março de 2017 disponível em <http://origemdapalavra.com.br/site/palavras/contato/>

Infopédia acessado em 30 de Março de 2017 disponível em <https://www.infopedia.pt/dicionarios/lingua-portuguesa/objetal >

Recebido em: 23 de agosto de 2017.

Aceito em: 10 de setembro de 2017. 